\title{
Pedunculated Giant Gastric Adenoma Embedded in the Entire Duodenum
}

\section{RB Bayramov*, RT Abdullayeva and SE Huseynova}

Thoracoabdominal Surgical Oncology Unit, Oncologic Clinic, Azerbaijan Medical University, Azerbaijan

*Corresponding Author: RB Bayramov, Thoracoabdominal Surgical Oncology Unit, Oncologic Clinic, Azerbaijan Medical University, Azerbaijan.
Received: May 07, 2020

Published: July 01, 2020

(C) All rights are reserved by RB Bayramov., et al.

\begin{abstract}
Introduction: Adenomatous polyps of the stomach are uncommon tumors, comprising only 7 - $10 \%$ of all gastric polyps. Most gastric adenomas are solitary, pedunculated masses, measuring up to $3-4 \mathrm{~cm}$ in size, and commonly located in the antrum.

Method: We present a patient with a giant pedinculated tubulovillous adenoma with features of moderate dysplasia developed in the middle third of the stomach and embedded in the entire duodenum and obturated it, who was referred to the hospital with clinical manifestations of duodenal obstruction. The correct diagnosis was made preoperatively at the specialized hospital on the basis of CT and upper gastrointestinal endoscopy.

Case Presentation: 44-year old female was admitted because if epigastric pain and vomiting. First upper gastrointestinal endoscopy carried out at an unspecialized hospital gave duodenal carcinoma obturating the lumen. Abdominal CT and upper gastrointestinal endoscopy in specialized center revealed giant gastric adenoma with long and thick pedicle embedded in the entire duodenum and obturated it. Middle segment gastric resection wit gastro-gastroanastomosis via laparotomy was carried out. The size of the adenoma's mass was $118 \times 10 \times 8 \mathrm{~cm}$, of the pedicle $-8 \times 4 \mathrm{~cm}$.

Conclusion: The case emphasizes that such giant gastric adenomas with a long pedicle can be embedded in the duodenum and obturate it completely causing the manifestations of duodenal obstruction. In unspecialized hospitals misdiagnosis can be made. Middle segment gastrectomy can be a preferential option in the case of middle third location of the giant gastric adenoma.
\end{abstract}

Keywords: Tumour; Duodenum; Giant Gastric Adenoma

\section{Introduction}

Polyps are defined as proliferative lesions of the gastrointestinal mucosa growing into the lumen [1]. Adenomatous polyps of the stomach are uncommon tumors, comprising only $7-10 \%$ of all gastric polyps [2]. WHO defines gastric adenomas as circumscribed, polypoid lesions composed of either tubular or villous structures lined by dysplastic epithelium [3]. Most gastric adenomas are solitary, pedunculated masses, measuring up to $3-4 \mathrm{~cm}$ in size, and commonly located in the antrum [4-6]. The incidence of gastric adenoma ranges from $0.5 \%$ to $3.75 \%$ in countries in the
Western hemisphere, whereas it is reported to occur between $9 \%$ and $20 \%$ in nations with a high risk of gastric cancer [7]. The magnitude of the risk of malignancy is not precisely defined, but is considered to be in the range of 5 - 15\%, which increases with the size of the tumor [6].

We present a patient with a giant pedinculated tubulovillous adenoma with features of moderate displasia embedded in the entire duodenum and obturated it. To the best of our knowledge this is the first case that has attained such a huge dimension and obturated the entire duodenum. 


\section{Case Presentation}

44-year old female was admitted because if epigastric pain and vomiting. 2 days ago upper gastrointestinal endoscopy was carried out at an unspecialized hospital and duodenal carcinoma obturating the lumen was considered. Over the mentioned diagnosis the patient was referred to the specialized oncologic clinic. CT revealed a mass filling the distal part of the stomach, the entire duodenum and the proximal short segment of the jejunum (Figure 1). The second upper gastrointestinal endoscopy carried out at the specialized hospital revealed a large and long pedicle in the stomach which was almost occupying the entire lumen of pylorus and descending to the duodenum and filling and obturating the latter by a tumor mass. A diagnosis of the giant pedinculated adenoma, arising from the middle third of the stomach (Figure 2) filling and obturating the entire duodenum was given on endoscopy. Pathological examination of biopsy specimens revealed tubular adenoma with mild dysplasia. Removing of the tumor by surgery was planned. During revision the enlarged and filled by soft tumor mass duodenum and proximal short segment of jejunum was observed. In order to extract the tumor mass from the duodenum and from the proximal part of the jejunum gastrotomy was carried out and a thick pedicle in the stomach was seen. Pulling the pedicle up was not able to get out the embedded tumor from the duodenum. Therefore we tried to pull the pedicle and push up the tumor from the lumen of the jejunum by the right index finger simultaneously and by this way the cauliflower-like growth measuring $18 \times 10 \times 8$ $\mathrm{cm}$ with a long and thick pedicle $(8 \times 4 \mathrm{~cm})$ got out gradually. Subsequently, middle segment gastric resection, end-to-end gastrogastroanastomosis was carried out. Postoperative period without any complications. Pathologic examination of excised tumor mass confirmed tubulovillous adenoma with signs of mild and moderate dysplasia. Surrounding gastric mucosa was revealed to be atrophic. No gastrointestinal complications after 4 years from surgery.

\section{Discussion and Conclusion}

The case emphasizes that such giant gastric adenomas with a long pedicle can be embedded in the duodenum and obturate it completely causing the manifestations of duodenal obstruction. In unspecialized hospitals misdiagnosis can be made. In our patient duodenal carcinoma was considered in unspecialized hospital on endoscopy and the correct diagnosis was made in the specialized clinic. Giant gastric adenomas with a thick pedicle must preferen-

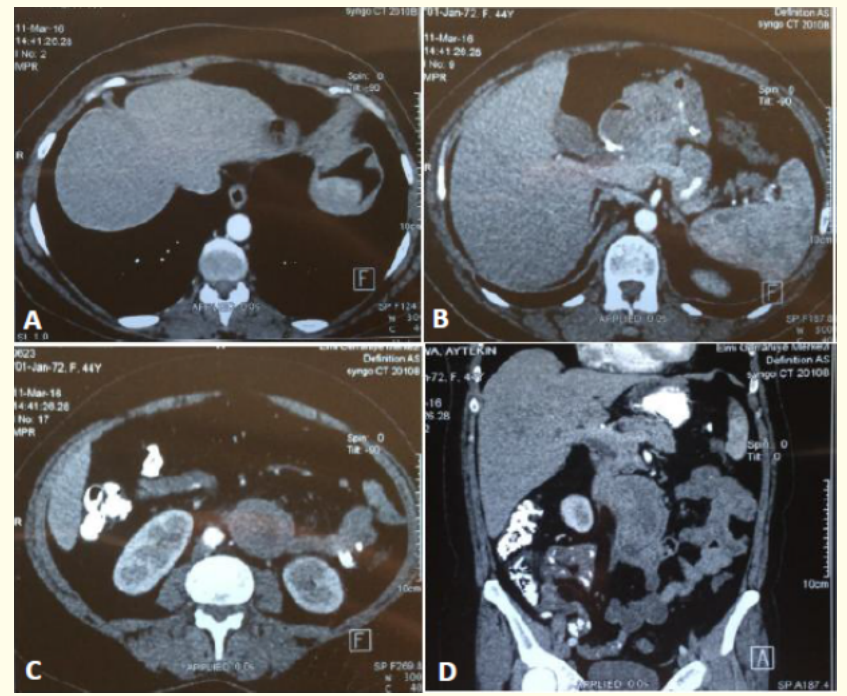

Figure 1: CT view of the gastric giant adenoma embedded in the duodenum. A - the thickened posterior gastric wall consistent with gastric neoplasia (axial view); B - the distal part of the stomach filled by tumor (axial view); C, D - the proximal segment of the jejunum filled by tumor mass (axial and coronal view, respectively).
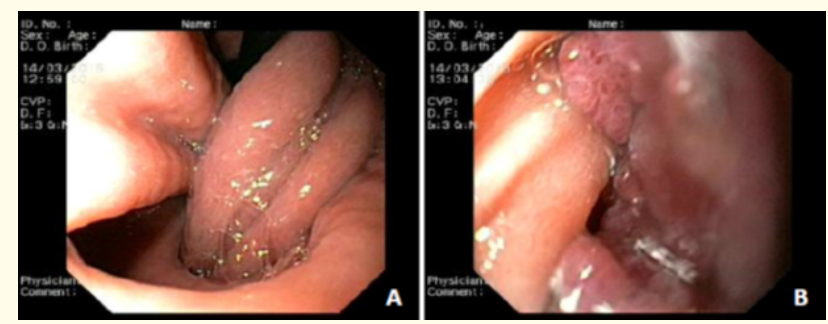

Figure 2: A - The thick and long pedicle of giant gastric adenoma protruding into the duodenum; B - The lumen of the duodenum obturated by the embedded giant gastric adenoma.

tially be removed by surgery and surgery can be performed as a gastric resection. In the case of middle third location of the giant gastric adenoma middle segment gastric resection with preservation of the stomach can be a preferential option.

Depending on the histological type, gastric adenomas may have a potential to become cancerous. Despite the general consideration 
about that small adenomas are usually tubular whereas large adenomas tend to be villous and to be getting malignant, such a huge adenoma of tubulovillous structure in our patient had no features of high-grade dysplasia.

\section{Bibliography}

1. Park Do Y and Lauwers G. "Gastric polyps: classification and management". Archives of Pathology and Laboratory Medicine 132 (2008): 633-640.

2. Ito H., et al. "Tubular adenoma of the human stomach. An immunohistochemical analysis of gut hormones, serotonin, carcinoembryonic antigen, secretory component, and lysozyme". Cancer 58 (1986): 2264-2272.

3. Hamilton SR., et al. "Pathology and genetics of tumours of the digestive system". WHO Classification of tumours. IARC Press (2000).

4. Guan CS., et al. "A Giant gastric adenoma embedded in the duodenum". Journal of College of Physicians and Surgeons Pakistan 25 (2015): S12-13.

5. Laxén F., et al. "Gastric polyps; their morphological and endoscopical characteristics and relation to gastric carcinoma". Acta Pathologica et Microbiologica Scandinavica 90 (1982): 221-228.

6. Abraham SC., et al. "Genetic alterations in gastric adenomas of intestinal and foveolar phenotypes”. Modern Pathology 16 (2013): 786-795.

7. Dudani Sh., et al. "Giant adenomatous polyp of stomach: case report of a rare tumor with unusual features". Japan Gastroenterological Endoscopy 5.1 (2014): 27-29.

\section{Assets from publication with us}

- Prompt Acknowledgement after receiving the article

- Thorough Double blinded peer review

- Rapid Publication

- Issue of Publication Certificate

- High visibility of your Published work

Website: www.actascientific.com

Submit Article: www.actascientific.com/submission.php

Email us: editor@actascientific.com

Contact us: +919182824667 